\title{
A INFLUÊNCIA DA CULTURA ORGANIZACIONAL NO PROCESSO DE INOVAÇÃO: O CASO DA ÁGUIA SISTEMAS DE ARMAZENAGEM EM PONTA GROSSA, PARANÁ
}

\section{Emilio Lourenço Morschel}

Especialista em Gestão Industrial pela Universidade Tecnológica Federal do Paraná - UTFPR emiliomorschel@gmail.com (Brasil)

\section{Verlaine Lia Costa}

Mestranda em Engenharia de Produção pela Universidade Tecnológica Federal do Paraná - UTFPR Professora do Centro de Ensino Superior dos Campos Gerais - CESCAGE

verlaine-@brturbo.com.br (Brasil)

\section{Dálcio Roberto dos Reis}

Doutor em Gestão Industrial pela Universidade de Aveiro, Portugal - UA

Professor da Universidade Positivo - UP

dalcioreis@utfpr.edu.br (Brasil)

\section{Eloiza Aparecida Silva Ávila de Matos}

Doutora em Educação pela Universidade Metodista de Piracicaba - UNIMEP

Coordenadora da Universidade Tecnológica Federal do Paraná - UTFPR

elomatos@utfpr.edu.br (Brasil)

\section{RESUMO}

O presente artigo tem como objetivo verificar se os processos de inovação desenvolvidos na Empresa Águia Sistemas de Armazenagem S.A., localizada no município de Ponta Grossa - Paraná são influenciados pela cultura organizacional da empresa. Para tanto, construiu-se uma revisão da literatura sobre cultura organizacional e inovação. Trata-se de uma pesquisa descritiva, com abordagem metodológica qualitativa, com dados quantitativos que complementam a análise de conteúdo, a partir da aplicação de três instrumentos de pesquisa, fundamentados nos estudos de Godoy (2009): Questionário de Caracterização da Empresa de Base Tecnológica e Processos de Inovação; Escala de Cultura da Inovação - ECI; e Roteiro para Entrevista com Gestor de P\&D. Os resultados evidenciaram que a cultura organizacional influencia profundamente os processos de inovação da indústria, verificando-se a existência de uma cultura de inovação solidificada na empresa.

Palavras-chaves: Cultura Organizacional; Inovação; Cultura de Inovação. 


\section{INTRODUÇÃO}

A cultura organizacional apesar de não ter um conceito universal, pode-se considerá-la como um conjunto de valores, crenças, pressupostos, percepções, normas, artefatos e padrões de comportamento, presentes nos objetivos, nas estratégias e na operacionalização da empresa, sendo que então, todas as decisões passam necessariamente pela cultura disseminada entre todos os membros da empresa, assim a cultura organizacional tanto poderá "ser um empecilho para o aumento da produtividade quanto um grande impulsionador para um alto nível de desempenho organizacional” (Santos, 2000, p, 14).

Todas as transformações que o mundo passou no século XX, com o advento da globalização, o acirramento da competição, os grandes avanços tecnológicos e comunicacionais, levam as organizações à mudanças e inovações, e as tecnologias tornam-se essenciais para a sobrevivência dessas empresas no mercado.

As inovações são crescentes, mas não poucas vezes a cultura organizacional não se modifica para absorver o impacto de todas as mudanças. Outras vezes, a inovação torna-se a base na qual se afirma a cultura da empresa, unidos em sua essência, visto que "toda empresa possui sua própria cultura, que diferencia a forma dela fazer as coisas e o pensar das pessoas que nela trabalham. Para inovar é imprescindível que essas pessoas compartilhem valores e pressupostos relacionados à inovação". (Horta \& Cabral, 2008, p. 3).

Diante dessas colocações, a questão norteadora de pesquisa foi: a cultura organizacional influencia os processos de inovação difundos na Empresa Águia Sistemas de Armazenagem localizada no município de Ponta Grossa - Paraná?

Visando responder a tal questionamento, objetiva-se no presente artigo verificar se os processos de inovação desenvolvidos na Empresa Águia Sistemas de Armazenagem S.A., localizada no município de Ponta Grossa - Paraná, são influenciados pela cultura organizacional da empresa.

Para tanto, realizou-se uma pesquisa na empresa, aplicando-se três instrumentos de pesquisas: Questionário de Caracterização da Empresa de Base Tecnológica e Processos de Inovação; Escala de Cultura da Inovação - ECI; e Roteiro para Entrevista com Gestor de P\&D, a partir dos quais foi possível atender ao objetivo proposto, respondendo a questão norteadora.

Este artigo está estruturado em quatro partes. A primeira é a presente Introdução. A segunda parte é formada pela Revisão da Literatura, abordando-se a questão da Cultura Organizacional e a 
Inovação. Na terceira parte, apresentam-se os Resultados e Discussões a partir da análise de conteúdo dos dados obtidos através da aplicação dos instrumentos de pesquisa. A quarta parte são as Conclusões.

\section{CULTURA ORGANIZACIONAL E INOVAÇÃO}

\subsection{Cultura Organizacional}

De acordo com Johann (2001), de uma maneira genérica, o termo cultura é usado para significar o conjunto de costumes, civilização e realizações e de outro lado, artes, erudição e demais manifestações mais sofisticadas do intelecto e da sensibilidade humana, consideradas coletivamente.

Para Freitas (1997) os elementos que compõem a cultura organizacional são: valores, estória e mitos, rituais e cerimônias; heróis, tabus, normas, símbolos e linguagem.

Com base nos elementos que compõe a cultura organizacional, Fleury e Fischer (1996, p. 6) dizem que:

a cultura organizacional é um conjunto de valores e pressupostos básicos expressos em elementos simbólicos, que em sua capacidade de ordenar, atribuir significações, construir a identidade organizacional, tanto agem como elemento de comunicação e consenso, como ocultam e instrumentalizam relações de dominação.

Levando-se em consideração os elementos da cultura organizacional, Cunha e Carmo (2007, p. 7) afirmam que a cultura organizacional é constituída de aspectos, que dão às organizações um modo particular de ser. Ela está para a organização, assim como a personalidade está para o indivíduo. Ela representa o conjunto de crenças, valores, estilos de trabalho e relacionamentos, que distingue uma organização das outras. A cultura molda a identidade de uma organização, assim como a identidade e o reconhecimento dos próprios funcionários.

Nesse sentido, cultura organizacional, para Santos (2003) servirá como um mecanismo de controle, atuando informalmente na aprovação ou proibição de determinados comportamentos.

De acordo com Luz (2009, p. 14), “a cultura organizacional influencia o comportamento de todos os indivíduos e grupos dentro da organização", entretanto, conforme Arruda (2006, p. 59) "Inovações organizacionais, como a adoção de uma nova tecnologia, o lançamento de um novo produto, uma nova forma de se analisar um processo ou de fazê-lo diferentemente, ou ainda uma nova forma de gestão, podem alterar a cultura organizacional".

Revista de Administração e Inovação, São Paulo, v. 10, n.2, p. 219-237, abr./jun. 2013. 
Diante da diversidade de definições de cultura organizacional, destaca-se ainda, conforme Godoy e Peçanha (2009, p. 145), "que o conceito de cultura organizacional utilizado integra: valores, crenças e pressupostos básicos inconscientes que são compartilhados por membros de uma organização, expressos através de normas, que podem ser observadas em rituais, palavras e ações”.

\subsection{Inovação}

De acordo com Reis (2004, p.43), as inovações tecnológicas "incluem novos produtos, processos, serviços e também mudanças nas tecnologias, em produtos, processos e serviços existentes”. Considera a inovação tecnológica como a principal forma de mudança nos dias atuais e que através disso se consiga obter vantagens competitivas e um crescimento empresarial ainda maior.

Entre as classificações das inovações tecnológicas, as mais usadas no teórico são as inovações em produtos e processos, além da disruptive innovation, ou inovações incrementais e radicais. (Christensen, 2002)

Para Laranja, Simões e Fontes (1997), especificamente, gradualmente, em decorrência dos investimentos, tempo e necessidades, as empresas podem promover melhorias e aperfeiçoar seus produtos, métodos e equipamentos de produção.

As formas mais empregadas, na inovação de produtos, de acordo com Temaguide (COTEC1997, II apud Fontanini e Carvalho, 2005) são:

a) Processo de tomada de decisão - para garantir a essência de cada produto tendo como relação os objetivos da organização;

b) Grupo de trabalho e gestão das interfaces - existente para a gestão de equipes multidisciplinares, para o trabalho na organização, interação entre ambientes externos com internos (ex. acionistas);

c) Visão compartilhada de projetos - vem para garantir as equipes de projetos, com a administração de recursos e autonomia para tal;

d) Estruturas apropriadas de projetos - traz modelos de estruturas matriciais, funcionais entre diversas outras, para a gestão de projetos;

e) Desdobramento da função qualidade - estruturada para um melhor desempenho e uma otimização no processo e desenvolvimento de produtos;

f) Outras ferramentas tais como Computer Aided Design (CAD) / Computer Aided 
Manufacture (CAM), protótipos, dentre outros.

Existem subdivisões em relação às inovações em produtos, sendo, produtos tecnologicamente novos e produtos tecnologicamente aprimorados. (OCDE - Manual de Oslo, 2004). Quando as características de um produto se diferem de outros já produzidos, aliando-se a estratégias de marketing, para uma relação de proximidade com novos compradores, além de estudos de aspectos socioeconômicos, é considerado um produto tecnologicamente novo.

Conforme Temaguide (COTEC-1998, I apud Fontanini e Carvalho, 2005), as ferramentas de gestão mais adequadas para as inovações em processos são:

a) Gestão de mudanças (Change management) - é onde acontece todo processo que tem envolvimento de mudanças, que tragam melhorias incrementais, seja para promover o produto e/ou processo, para diminuir o uso de custos, aumento de produção, entre outros.

b) Melhoria contínua - é um conjunto de ferramentas voltadas ao planejamento e monitoramento das mudanças nas empresas, para que resultem em melhoria do desempenho.

c) "Pensamento enxuto" (Lean thinking) - reflexão das atividades relacionadas aos processos situados interna ou externamente na organização, mostrando e eliminando atividades que não tragam valor e desperdícios.

Ainda de acordo com Temaguide (COTEC-1998, I apud Fontanini e Carvalho, 2005), a cultura na transição e a sobreposição de resistências às inovações também precisam de um gerenciamento, tão como planejamento e modernização das inovações nos processos.

Segundo o Manual da Inovação (Mattos et al., 2008), ocorre Inovação incremental quando há uma melhora ou aperfeiçoamento no que se faz ou no jeito feito, deixando os produtos mais ergonômicos, transformando o produto mais visual, ou também adicionando utilidades que o diferenciem, tornando-o mais desejado pelos compradores, trazendo uma maior competição ou uma Inovação radical , quando novas ideias trazem como resultado novos produtos ou processos, nunca antes vistos.

\section{METODOLOGIA}

A questão entre cultura da inovação entrelaçada na cultura organizacional ainda é um tema Revista de Administração e Inovação, São Paulo, v. 10, n.2, p. 219-237, abr./jun. 2013. 
recente, caracterizando a presente pesquisa como descritiva, a qual de acordo com Gil (1999), pressupõe o uso de ferramentas de coleta de dados padronizadas - questionários e escalas. A abordagem metodológica é qualitativa, uma vez que traz o olhar daqueles que participam efetivamente dos processos produtivos da empresa, em paralelo com o olhar do pesquisador, que busca compreender sentidos diferenciados, apesar de prescindir de alguns dados quantitativos para subsidiar a análise.

Segundo Vieira (2004, p. 15), "por vezes é difícil classificar um método como qualitativo ou quantitativo, uma vez que informações qualitativas podem ser contadas e informações quantitativas podem ser interpretadas". Assim, o ideal é que a investigação de diferentes problemas seja realizada a partir de visões tanto qualitativas quanto quantitativas, visto estas serem complementares.

Os instrumentos de pesquisa utilizados foram fundamentados nos estudos de Godoy (2009), uma vez que estes instrumentos se adequavam perfeitamente ao objetivo do Estudo de Caso da Empresa Águia Sistemas de Armazenagem S.A, visto que, conforme Godoy (2009, p. 4), “os resultados das revisões bibliográficas deste trabalho, apontam para a existência de estudos que relacionam inovação e cultura organizacional" e especificamente sobre sua pesquisa, afirma que "os dezenove (19) estudos encontrados mostram a importância da ampliação do entendimento da cultura organizacional para a melhoria dos processos de inovação. A influência da cultura organizacional sobre os processos de inovação foi confirmada pelos estudos, contudo, alguns deles alertam que ela pode ter cunho positivo ou negativo, dependendo dos valores organizacionais envolvidos”.

Os instrumentos aplicados na empresa foram: Questionário de Caracterização da Empresa de Base Tecnológica e Processos de Inovação; Escala de Cultura da Inovação - ECI; e Roteiro para Entrevista com Gestor de P\&D.

Os participantes da pesquisa foram: o Diretor Comercial e Industrial (Entrevistado 1); o Diretor Administrativo Financeiro (Entrevistado 2); a Gerente de Recursos Humanos (Entrevistado 3); e um Engenheiro, um dos responsáveis técnicos por Pesquisa e Desenvolvimento (Departamento de Desenvolvimento de Produtos e Processos) (Entrevistado 4).

A direção da empresa assinou um Termo de Consentimento Livre e Esclarecido, onde se evidenciou os objetivos, quais instrumentos de pesquisa seriam aplicados, a inexistência de riscos, concordando com os termos da pesquisa em atendimento aos princípios éticos de pesquisas com seres humanos, permitindo a divulgação dos resultados desta pesquisa.

Os dados foram analisados de acordo com a Análise de Conteúdo descrita por Bardin (2002), por permitir a apreensão nos discursos, dos valores, crenças, opiniões e sentimentos dos participantes, 
o que torna-se imprescindível para que se possa verificar se a cultura organizacional influencia os processos de inovação na empresa.

\section{RESULTADOS E DISCUSSÃO}

\subsection{Caracterização da Empresa e Processos de Inovação}

A Empresa Águia Sistemas de Armazenagem S.A. se originou de uma pequena empresa do setor de metalurgia, Metalúrgica Águia, fundada em 1973, e hoje faz parte da holding ASA PARTICIPAÇÕES, juntamente com a Águia Química e a Águia Florestal Indústria de Madeiras.

Inovação é uma característica que faz parte da trajetória da empresa. Seu fundador, Sr. Ferdinando Scheffer Júnior, mecanógrafo, obteve a empresa Rena S/A em São Paulo e devido ao início do processo de industrialização no município de Ponta Grossa, transferiu a empresa para o município em 1970 e "juntamente com o engenheiro eletrônico Pablo Stierlli, iniciou o projeto da primeira máquina registradora eletrônica no Brasil, que não chegou a ser concluído devido a um incêndio que destruiu completamente a indústria, suas máquinas e seu estoque”. (Entrevistado 1)

Após a reconstrução da empresa, em 1972, passaram a desenvolver o copiador a álcool, o que seria a copiadora, tipo Xérox, da época, com requintes de tecnologia que superava radicalmente o único concorrente que era produzido pela sueca Facit. Este produto atraiu a atenção de algumas empresas e então a Rena foi vendida, quando no ano seguinte deu-se início a Metalúrgica Águia, cujo negócio era a fabricação de móveis de aço. (Entrevistado 1)

A partir da criação da Metalúrgica Águia em 1973, pode-se estabelecer uma cronologia de seu desenvolvimento e crescimento no setor industrial brasileiro: 
A influência da cultura organizacional no processo de inovação: o caso da Águia sistemas de armazenagem em Ponta Grossa, Paraná

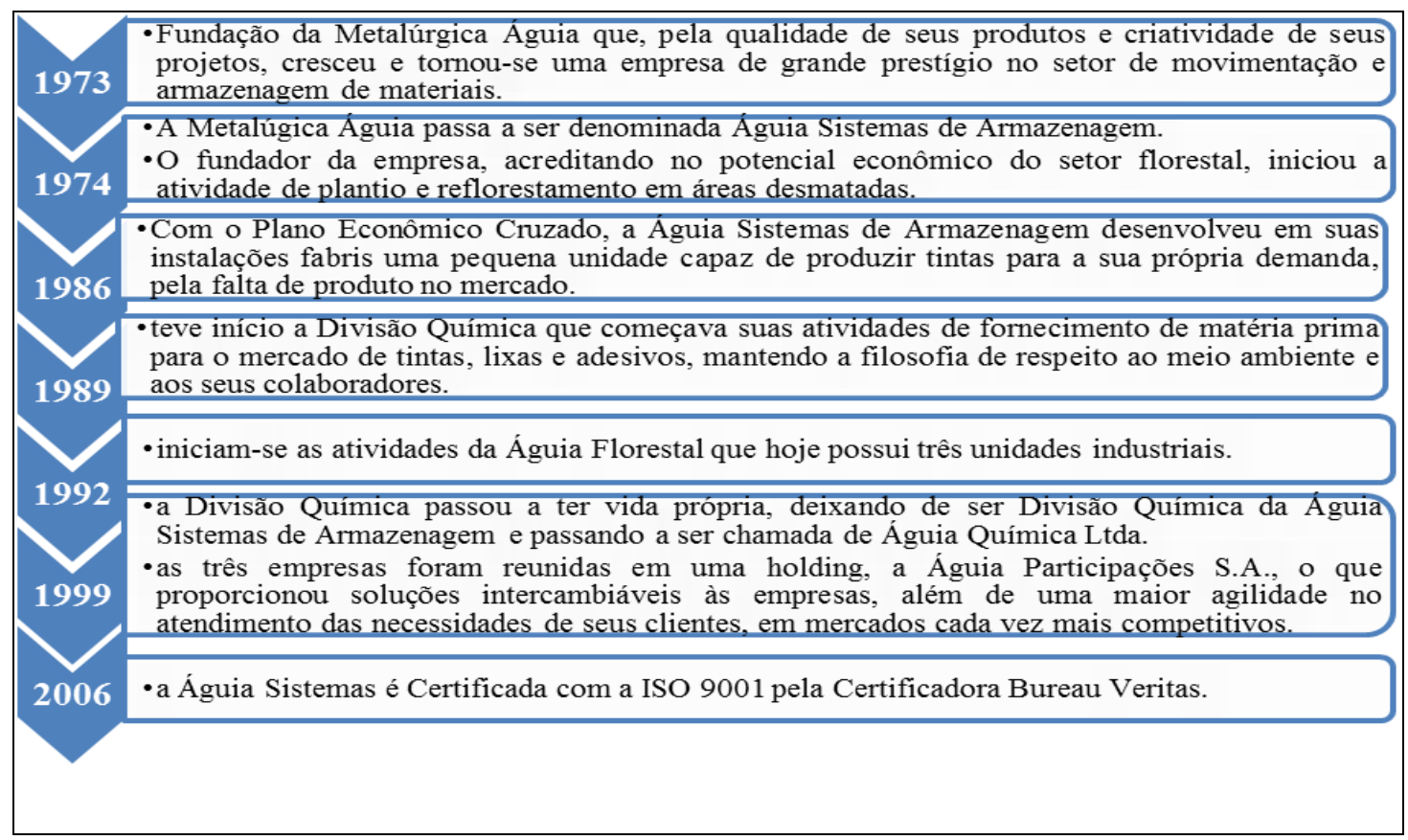

\section{Figura 1 - Cronologia da Empresa Águia Sistemas de Armazenagem.}

Fonte: Elaborada pelo autor a partir de entrevista com o Diretor Administrativo-Financeiro, Sr. Renato Motta Bechtold, 2011.

Atualmente a Águia é considerada a principal indústria do setor de movimentação e armazenagem no Brasil. Seu quadro funcional conta com 995 funcionários, sendo que o nível educacional está acima do verificado na indústria em geral no Brasil. Conforme o Gráfico 1, 37\% (370) tem o Ensino Fundamental; 50\% (501) o Ensino Médio; 12\% (114) o Ensino Superior e 1\%(10) Pós-Graduação.

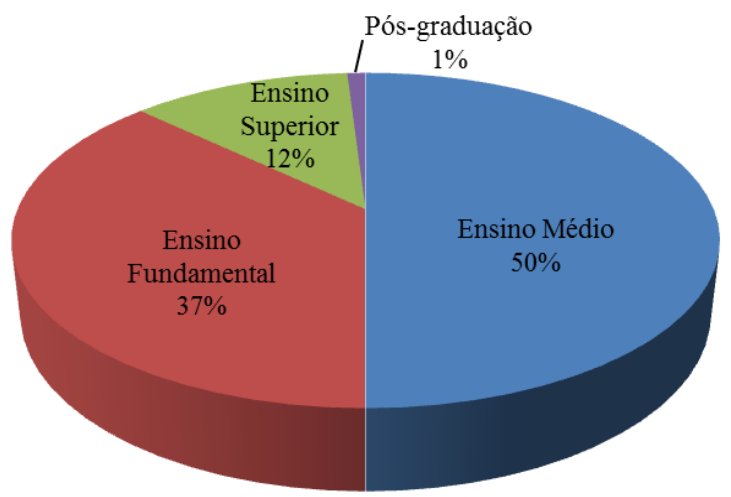

\section{Gráfico 1 - Nível Educacional dos Funcionários da Águia Sistema de Armazenagem.} Fonte: Dados da pesquisa, 2011. 
Destaca-se que com a modernização da indústria brasileira, a capacitação dos funcionários tem se tornado uma exigência cada vez maior. De acordo com o Ministério do Trabalho e Emprego (Nível de Escolaridade..., 2010, p. 1),

Há 20 anos, apenas 16\% dos trabalhadores tinham o segundo grau completo. Em 2000, este percentual subiu para 26\%. Em 2008, o mais recente levantamento da RAIS Relação Anual de Informações Sociais mostrou que este total estava em 45\%. A evolução do setor também levou os profissionais para os bancos das universidades nos cursos de graduação e até mesmo mestrado. Do total de 9,8 milhões de empregados em 2008, 652.165 tinham nível superior completo e 2.127 concluíram o mestrado.

Analisando-se a questão das inovações radicais e incrementais em produtos e processos, tem-se a ocorrência de um mix de inovações, visto que, "as inovações radicais em produtos são uma constante na empresa, uma vez que o produto vai sendo modificado de acordo com o uso, com o tempo, com as sugestões, pedidos dos clientes, exigências do mercado e pela influência da concorrência." (Entrevistado 2)

Quanto às inovações radicais em processos, também a empresa não consegue definir numericamente, pois segundo Entrevistado 2,

São inúmeras: nas linhas de pintura, no corte a laser, foram adquiridas perfiladeiras novas, construída uma nova fábrica dedicada á produção de longarinas, automatização de alguns processos, adquirida uma dobradeira CNC, implantado um robô na fabricação de containers, modernizado o processo de solda de partes dos aramados.

No caso da empresa, para a inovação do produto torna-se indispensável a melhoria do processo, tendo assim a empresa um "mix muito grande de processos e produtos". (Entrevistado 2)

$\mathrm{Na}$ concepção dos dirigentes da empresa, em relação às inovações incrementais em produtos, existem inovações praticamente todos os dias, pois, "quando da entrega e montagem de um produto, os montadores e os próprios clientes solicitam e sugerem mudanças e aperfeiçoamentos nos produtos. Há um processo de melhoria constante, tanto no produto como no processo." (Entrevistado 2)

Em relação às inovações incrementais geradas nos processos, estas ocorrem na medida em que as equipes de montagem, estimuladas pelo gestor para trazerem sugestões, estão sempre em busca de melhorias.

Tem-se que a empresa adota como ferramenta para a inovação tanto de produto quanto de processo a Gestão da Melhoria Constante, definida como um processo de inovação incremental, focada e contínua que envolve toda a organização sendo um processo complementar às mudanças radicais (Gonzalez e Martins, 2006). Entretanto, conforme o Entrevistado 1, "A GMC - Gestão da Melhoria 
Contínua é um processo que contribuiu muito no passado, percebe entretanto que hoje deu uma pequena desacelerada".

Observa-se estar ocorrendo na Águia a falta de sustentação dos programas de melhoria na cultura organizacional, de acordo com o que destaca Gonzalez e Martins (2006, p. 1)

É evidente, em diversas organizações, que existe um consenso em relação à necessidade de mudar e melhorar constantemente seus processos a fim de atender as exigências dos clientes. Contudo, percebese que muitos programas de melhoria enfatizam apenas o lado técnico, não se atentando à necessidade de uma revolução comportamental que tal prática encerra. Assim, quando não sustentados por uma cultura organizacional que os fomentem, os programas de melhoria acabam terminando com a mesma rapidez com que se iniciaram, promovendo uma insatisfação por parte dos indivíduos envolvidos nas ações de melhoria.

Assim, em relação às inovações radicais e incrementais em produtos, a Águia oferecendo uma linha especial de produtos para infraestrutura de logística, no que se refere a soluções em movimentação e armazenagem, desenvolvendo projetos de acordo com as necessidades de cada cliente, atendendo a demanda de diversos segmentos, tais como têxteis, alimentícios, eletroeletrônicos, automobilístico, construção civil e outros segmentos como atacadista e de autosserviço, tanto indústrias no Brasil quanto no exterior. Seus principais produtos são: Porta Pallets; Autoportantes; Mini Loads; Porta Pallets com corredores estreitos; Porta Pallets com corredores deslizantes; Drive in/Drive Through; Armazenagem dinâmica paletizada; Push back; Mini porta pallets; Flow racks; Transportadores; Mezaninos; Containers Tubulares; Containers aramados; Containers especiais; Acessórios; Planos Aramados, sendo que "A maioria dos produtos objetiva a verticalização dos espaços disponíveis para armazenamento de estoques de forma simples e seletiva”. (Entrevistado 2)

Em relação às inovações radicais e incrementais em processos, a Águia Sistemas está posicionada como integradora de soluções customizadas de movimentação e armazenagem, com alianças estratégicas estabelecidas oficialmente com as empresas provedoras de tecnologia em sistemas de movimentação e picking e de tecnologia em transelevadores de forma integrada em áreas de separação de pedido e armazenagem.

\subsection{Cultura Organizacional}

De acordo com a Gerente de Recursos Humanos da empresa, a cultura da organização é 
relativamente paternalista, com certa dose de centralização nas decisões, contudo o processo de validação é formal sempre documentado e assinado. A influência e o apoio dos gestores para determinadas ideias proporcionam maior ou menor velocidade nos processos de mudanças.(Entrevistada 3)

O paternalismo é um traço, ainda hoje marcante da cultura organizacional brasileira, caracterizando-se, por apontar no país, "para a coexistência de uma face afetiva, um tipo de pai que provê, mas exige obediência absoluta.”. (Moreira, 2005, p. 909).

A questão afetiva e emocional é enfatizada como um traço muito forte nas decisões na Águia: As decisões muitas vezes são mais emocionais do que reacionais, nos processos de mudança $e$ inovação. Em certas épocas, determinadas áreas avançam, inovam, melhoram e em outros momentos isto acontece com menor intensidade. Verifica-se, por exemplo, quando grande parte das atenções se foca para uma novidade, um novo produto que acaba sendo a prioridade do momento, em detrimento de outros já existentes. (Entrevistado3)

Quanto às lideranças, estas são consideradas as "inspiradoras do processo inovativo, sendo os responsáveis pelo desenvolvimento das pessoas, e tem que se preocupar com a adaptação destas pessoas" (Entrevistado3)

Mesmo apoiada em uma cultura organizacional relativamente paternalista com decisões tomadas com certa dose de emoção, os principais valores da empresa são a transparência, o respeito às pessoas, o empreendedorismo e a inovação.

O ponto forte da empresa é a cultura de inovação. "A informalidade da gestão ajuda, torna as mudanças fáceis e rápidas". De acordo com Pelegrino (2009, p. 1), "o principal é preparar a equipe para as mudanças e introduzir uma nova cultura na empresa". "é preciso incentivar novas atitudes comportamentais nos funcionários por meio de orientação e treinamento. O objetivo é tornar os colaboradores verdadeiros agentes da inovação".

Assim, pode-se perceber que a cultura organizacional partilhada pelos membros da empresa, ou seja, a cultura dominante, aquela que caracteriza a personalidade da organização é a cultura da inovação.

\subsection{Cultura da Inovação}

A partir da análise da Cultura Organizacional da Águia Sistemas de Armazenagem S.A., levando-se em conta que, de acordo com Godoy e Peçanha (2009, p. 144), que "a cultura organizacional que facilita o desenvolvimento de processos inovativos é denominada na literatura 
A influência da cultura organizacional no processo de inovação: o caso da Águia sistemas de armazenagem em Ponta Grossa, Paraná

como Cultura da Inovação", verifica-se que na busca por vantagens competitivas diferenciadas, a inovação vem adquirindo crescente importância, sendo que, "uma cultura organizacional que facilite estes processos torna-se fator estratégico para que a empresa alcance seus objetivos".

Para analisar a questão da Cultura da Inovação, com base na Escala de Cultura da Inovação ECI, formulado por Godoy (2009) e a Dra. Dóris L. Peçanha, obteve-se o Gráfico 2:

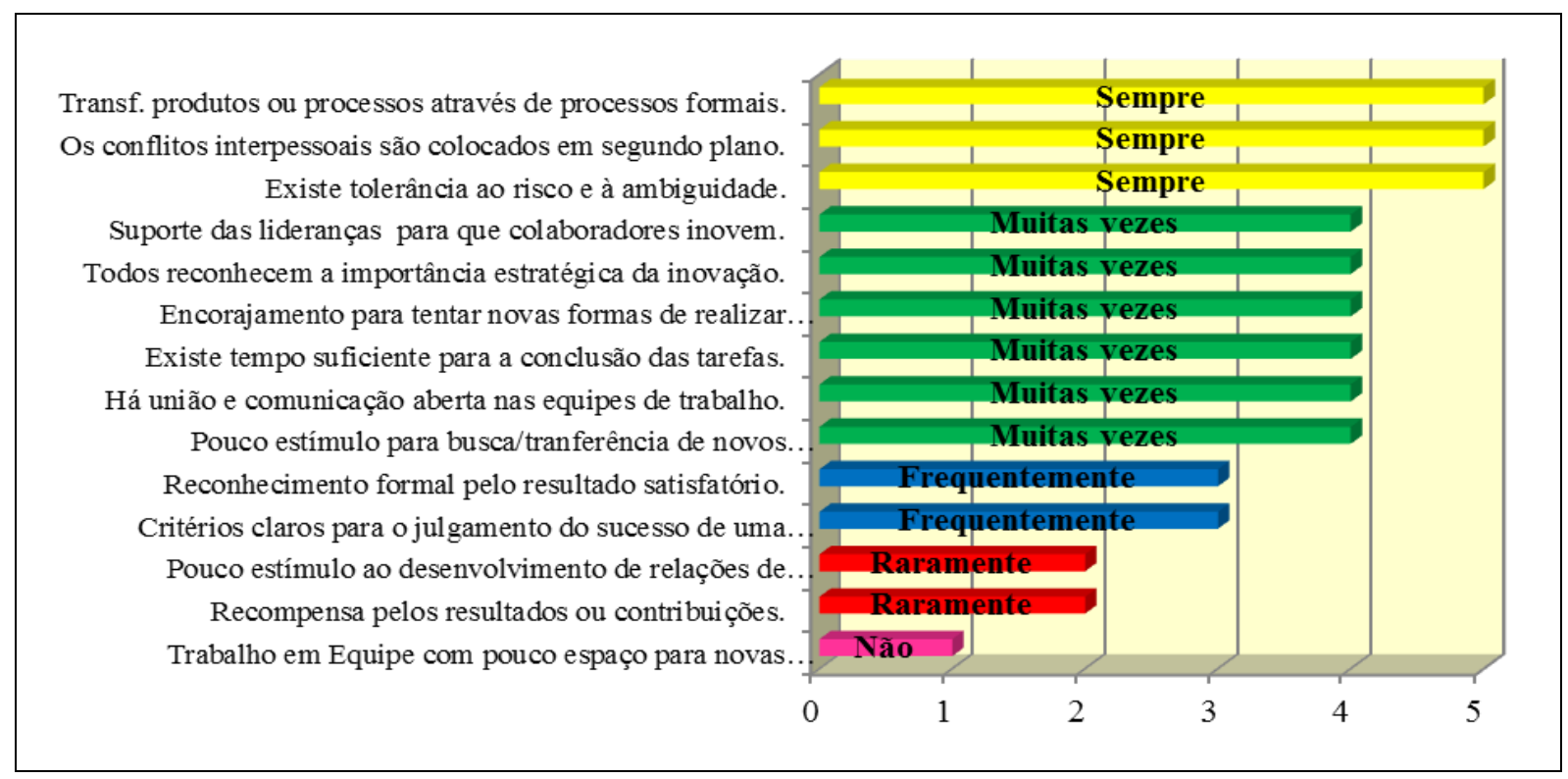

Gráfico 2 - Escala de Cultura da Inovação - ECI.

Fonte: Dados da Pesquisa, 2011.

De acordo com o Diretor Comercial e Industrial da Águia Sistemas de Armazenagem, SEMPRE existe tolerância ao risco e à ambiguidade, não havendo culpabilização pelo erro. Essa situação é reforçada pela fala de um dos engenheiros responsáveis pelo $\mathrm{P} \& \mathrm{D}$, pertencente ao Departamento de Desenvolvimento de Produtos e Processos: "Não há uma gestão destes riscos Na maior parte dos casos se tenta dimensionar, em geral a empresa assume compromissos (nas inovações) sem dimensionar estes riscos, principalmente em relação ao desenvolvimento, produção e entrega". "Ao arriscar acabam errando e depois têm que consertar. Os erros não são condenados". (Entrevistado 1)

De acordo com Cavalheiro (2010, p. 49)

geralmente, costuma-se assumir que empreendedores são mais tolerantes ao risco. (...) o empreendedor é autoconfiante, autônomo, independente, persistente e pesuasivo, o que faz com que ele, em tese, seja mais propenso ao risco em comparação a pessoas sem o mesmo perfil. Contudo, o excesso de confiança pode dificultar o sucesso do empreendedor, fazendo com que o mesmo aceite riscos excessivos.

Revista de Administração e Inovação, São Paulo, v. 10, n.2, p. 219-237, abr./jun. 2013. 
SEMPRE, os conflitos interpessoais são colocados em segundo plano, pois, segundo a Gerente de RH, “O nível de interação das equipes é bom e facilmente administrável. O embate entre produção e comercial é bom, a produção corre riscos altos para conseguir atender ao comercial. Diretor comercial e industrial é o mesmo e isto facilita o processo" (Entrevistada 3), sendo que RARAMENTE existe pouco estímulo ao desenvolvimento de relações de confiança, ao contrário, existe estímulo aos liderados, não havendo "qualquer tipo de apropriação de ideias", (Entrevistado 4) sendo que assim, MUITAS VEZES as lideranças oferecem suporte para que os colaboradores inovem.

De acordo com Horta e Cabral (2008, p. 8),

\begin{abstract}
É importante que os líderes conheçam o mais profundamente possível a cultura da empresa em que atuam, que sejam conscientes do seu poder de influência e éticos em relação a isso, e que direcionem o desenvolvimento desses valores para um aumento da probabilidade de sucesso da empresa (e não de pequenos grupos dentro da empresa) em longo prazo - algumas práticas podem funcionar em curto prazo, mas diminuem a probabilidade de sucesso da empresa no futuro. Os líderes, sejam os sócios fundadores ou diretores, devem ter consciência do quanto seus comportamentos e visões influenciam as percepções e ações das pessoas no dia-a-dia da empresa. Devem saber que podem precisar quebrar alguns paradigmas pessoais para então quebrar paradigmas culturais.
\end{abstract}

SEMPRE, que há necessidade de transformações em produtos ou processos, elas ocorrem principalmente através de processos formais, "viram processos, a transferência ocorre muito em função das regras da ISO, documentos, reuniões, treinamentos. Aproveitam assim para construir os processos, fluxos, instruções de trabalho, o que traz as mudanças para toda a organização" (Entrevistado 4). Porém, FREQUENTEMENTE não existem critérios claros para se julgar o sucesso de uma inovação, sendo que as atividades de inovação não são permanentemente monitoradas, visto que "Isto não é um processo dentro da organização - acontece de forma experimental e natural, em varias áreas, com ferramentas distintas". (Entrevistado 4)

MUITAS VEZES o estímulo pode parecer pequeno para que as pessoas busquem novos conhecimentos, transfiram conhecimentos adquiridos, transformem-os em ações e os documentem. Entretanto, a empresa desenvolve um programa de treinamento anual com revisões semestrais, alimentado pelos resultados do processo de avaliação de desempenho. Faz-se a qualificação individual e em equipes. Neste momento, se avaliam as entradas de novas tecnologias na organização. Tudo é planejado e orçado. "O orçamento para desenvolvimento é $5 \%$ da folha de pagamento. São previstos neste orçamento - treinamentos, palestras, benchmarkings, incentivos à educação (a empresa subsidia cursos técnicos, graduação, especialização - paga de 10 a 100\% - dependendo do retorno que esta formação poderá trazer para a empresa". (Entrevistado 3)

Revista de Administração e Inovação, São Paulo, v. 10, n.2, p. 219-237, abr./jun. 2013. 
Para a Gerente de Recursos Humanos, esta é uma boa estratégia de retenção. No caso do auxilio educação para fazer um curso com 2 anos de duração, há que se ter dois anos de casa, para um curso de 5 anos, precisa ter 5 anos de casa. Exigem contrapartidas, se reprovar por faltas ou por notas são desligados do programa. (Entrevistado 3)

A qualificação dos Recursos Humanos possibilita condições mais sólidas para que as empresas possam inovar e se colocarem à frente de seus concorrentes, preceito que embasa a Lei de Inovação: "as empresas inovadoras podem abater até $160 \%$ do total investido em pesquisa e desenvolvimento (P\&D) do Imposto de Renda, mas este percentual pode chegar a $200 \%$, caso as empresas possuam mestres e doutores entre seus quadros" (Chiozzini, 2005, p. 20)

MUITAS VEZES há união e comunicação aberta nas equipes de trabalho. Estão incentivando agora maiores discussões entre as equipes. "A criação de equipes com pessoas de diferentes áreas, e com diferentes responsabilidades, certamente agilizará e facilitará ainda mais o processo de inovação". (Entrevistado 3).

MUITAS VEZES Existe tempo suficiente para a conclusão das tarefas, apesar da equipe de desenvolvimento ser pequena para um grande volume de inovações, uma vez que são 12 pessoas no desenvolvimento de produtos, equipe está dividida, uma parte para a estrutura estática (convencional) e uma estrutura de movimentação / motorizada. Alguns profissionais atuam nas duas áreas (estática e motorizada). Também têm uma equipe com melhorias e qualidade. Analisam falhas ou problemas $e$ estão constantemente melhorando os projetos. Estas equipes e esta estrutura foram implementadas recentemente em decorrência da necessidade de maior agilidade na realização dos projetos. (Entrevistado 4)

MUITAS VEZES, cada pessoa é encorajada a tentar novas formas de realizar suas atividades. Na Empresa existe o PPR, Programa de Participaçao nos Resultados que estimula a participação e o trabalho em equipes (não há previsão de pagamentos ou prêmios para inovação), e a "Gestão de competências - avaliam as pessoas com o potencial de inovação e criação - criou-se uma escala de critérios com a quantidade de inovações que o profissional produziu no setor dele" (Entrevistado 4). NÃO acontece na empresa de haver pouco espaço para exposição de ideias/realização de novas ações nos trabalhos em Equipe. Assim, FREQUENTEMENTE há reconhecimento formal quando o colaborador atinge resultado satisfatório. A pessoa que se destaca é designada para oportunidades de trabalhar em processos ainda maiores, e acaba tendo mais oportunidades de desenvolvimento em outras áreas ou em outros grupos. Dependendo da capacidade, o profissional pode ascender a instrutor

Revista de Administração e Inovação, São Paulo, v. 10, n.2, p. 219-237, abr./jun. 2013. 
de processo Kaizen; e, RARAMENTE os colaboradores não são recompensados pelos resultados que atingem ou contribuições originais que ofereçam. A Águia mantem o programa de Gestão da Melhoria Contínua, através do qual se recompensa as sugestões e soluções apontadas pelos colaboradores, que entram num ranking (não relacionadas a mudanças que gerem economia ou aumento de produtividade). "Estas mudanças devem estar relacionadas a mudanças que beneficiam a maioria das pessoas. Neste caso, são recompensados em prêmios (eletrodomésticos, viagens), nunca em dinheiro. As recompensas em dinheiro estão no PPR - Programa de Participação nos Resultados". (Entrevistado 4)

Jager et al. (2004) sugerem um modelo para a prática da melhoria contínua, sustentado pelo lado humano e cultural que envolve tal processo.

Os autores definiram quatro pilares ou precondições necessárias para garantir a prática da melhoria contínua por todos os funcionários: entendimento, competências, habilidades e comprometimento. Inicialmente, o modelo requer o entendimento, por parte de todos, do "por que" a melhoria é importante e exatamente como se dará a contribuição individual para êxito dessa atividade. As pessoas necessitam possuir competências e conhecimentos para a solução de problemas que habilitam a sua participação por meio de ideias, sugestões e execuções. Finalmente, os indivíduos devem estar motivados em colocar esforço extra para melhorar os processos. (Gonzalez e Martins, 2006, p. 3)

Finalmente, pode-se dizer que MUITAS VEZES todos reconhecem a importância estratégica da inovação, visto que a Águia é uma empresa essencialmente inovadora e que em sua história viveu constantes mudanças e adaptações e que agora neste ano vem vivendo novas mudanças. "Estão abrindo uma nova frente de negócios chamada - Águia Sistemas Construtivos, que atuará na construção de casas e escritórios com tecnologia internacional que permitirá economia, facilidades $e$ agilidade no processo de construção de casas". (Entrevistado 3).

Toda essa perspectiva de cultura de inovação instalada na Águia tem fundamento na afirmação de um dos engenheiros responsáveis pelo P\&D: “A Águia é uma empresa inovadora, pode parecer que no mercado tudo já esta criado, mas para a Águia sempre é uma inovação”. (Entrevistado 4).

Assim, se a ideia é que a cultura da empresa deve favorecer a inovação, é essencial que se mantenha atento à cultura organizacional difundida na empresa, cabendo aos lideres buscar o fortalecimento dos valores e processos que impactem positivamente o desenvolvimento de projetos de inovação. Investigar quais são as práticas da empresa em cada processo e produto, em relação à cultura de inovação relacionando os elementos da cultura organizacional com as propostas para a gestão da inovação e trabalhar em prol da sensibilização, educação e participação de grande parte da empresa, Revista de Administração e Inovação, São Paulo, v. 10, n.2, p. 219-237, abr./jun. 2013. 
são os primeiros passos para a solidificação de um processo de inovação influenciado pela cultura organizacional, os quais poderão emergir sem resistências e incorporados pelos funcionários.

\section{CONSIDERAÇÕES FINAIS}

A Águia Sistemas de Armazenagem é uma empresa que traz na raiz a cultura e o incentivo à melhoria e à mudança. Desde a fundação da empresa, mostrou-se empreendedora e arrojada que em toda a sua vida empresarial se pautou pela mudança e pela inovação.

Sempre atento às mudanças e às oportunidades de mercado o fundador buscou atualizar-se tecnologicamente em produtos e em soluções que o mercado local e nacional demandavam. Esta forma de ver o mercado, a concorrência e os clientes foi repassada e apreendida pelos filhos que atualmente comandam as organizações que compõem o grupo empresarial e estão disseminando esta cultura entre os demais diretores, liderados e as equipes de técnicos e profissionais. O filho que dirige a Águia Sistemas de Armazenagem é um incentivador e estimulador da mudança e da inovação na organização, já que visita e participa de feiras nacionais e internacionais do segmento, realiza viagens e visitas internacionais em busca de novas tecnologias, produtos, participa das discussões das melhorias em processos e em produtos, está diariamente no departamento de engenharia e na produção, observando, analisando, criticando, enfim participando e vibrando com os produtos e soluções criados e inovados. Esta característica sem dúvida se reflete no comportamento dos diretores, gestores e nas equipes que buscam aplicar o que observam.

Além das características culturais dos dirigentes, a empresa ao longo dos últimos anos, com o auxílio de consultorias especializadas, desenvolveu, implantou e mantém metodologias como o Sistema de Gestão pela Qualidade, o Kaizen, o GMC - Gestão da Melhoria Continua, o PPR Programa de Participação nos Resultados, e também programas de treinamento e desenvolvimento profissional que têm assegurado a retenção dos talentos, a formalização, documentação e a continuidade do processo de inovação na organização.

O relativo paternalismo, a informalidade na gestão e o caráter emocional observado em muitas decisões, traços culturais desta organização, têm sido percebidos como os grandes estimuladores do processo de inovação na empresa, e têm contribuído para o seu crescimento e para a manutenção em posição de destaque no segmento em que atua, caracterizando-se como empresa com cultura 
inovadora.

Por fim deve-se evidenciar que a presente pesquisa ainda apresenta como limitação não ter analisado a questão da cultura organizacional e a cultura de inovação sob o ponto de vista das equipes de trabalho, abrindo-se assim a possibilidade da realização de futuras pesquisas que poderão dar uma visão mais aprofundada, podendo contribuir para mudanças que reflitam-se no fortalecimento da cultura de inovação da empresa.

\section{REFERÊNCIAS}

Bardin, L. (2002). Análise de conteúdo. Lisboa: Edições 70.

Cavalheiro, E. A. Tolerância ao risco: uma análise sob a ótica comportamental. (2010). Santa Maria (RS): Universidade Federal de Santa Maria. [Dissertação de Mestrado em Administração].

Chiozzini, D. (2005). Capacitação: peça-chave para obter vantagens competitivas. Inovação Uniemp [online]. 1 (3), 20-21.

Christensen, C.M. (2002). The innovator's dilemma: the revolutionary national bestseller that changed the way we do business. New York: Harper Business.

Cunha, C.; Carmo, S. do. (2007) A cultura e o clima organizacional e suas consequências no planejamento de carreira. Belém.

Fleury, M. T. L. (1996). O desvendar a cultura de uma organização - uma discussão metodológica. In: Fleury, Maria Tereza L.; Fischer, Rosa Maria (coordenadoras). Cultura e Poder nas Organizações.2. ed. São Paulo: Atlas.

Fontanini, J. I. C., Carvalho, H. G. de. (2005, Novembro). As inovações incrementais em processos e seus fatores contribuintes em um ambiente industrial - um estudo de caso. XXV Encontro Nac. de Eng. de Produção - Porto Alegre, RS, Brasil, 29.

Freitas, A. B. de. (1997). Traços brasileiros para uma análise organizacional. In: Motta, Fernando C. Prestes e Caldas, Miguel P. (org) Cultura organizacional e cultura brasileira. São Paulo: Atlas.

Gil, A. C. (1999). Métodos e técnicas da pesquisa social. São Paulo: Atlas.

Godoy, R. S. P. de. Relações entre cultura organizacional e processos de inovação em empresas de base tecnológica. (2009). São Carlos. [Dissertação de Mestrado em Engenharia da Produção da Escola de Engenharia de São Carlos da Universidade de São Paulo, sob a orientação da Prof. ${ }^{a}$ Dra. Dóris Lieth Nunes Peçanha].

Godoy, R. S. P. de; Peçanha, D. L. N. (2009). Cultura Organizacional e processos de inovação: um estudo psicossociológico em empresa de base tecnológica. Boletim Academia Paulista de Psicologia,

Revista de Administração e Inovação, São Paulo, v. 10, n.2, p. 219-237, abr./jun. 2013. 
$29(1), 142-163$.

Gonzalez, R. V.; Martins, M. F. (2006, Outubro). Cultura organizacional: base para a sustentabilidade dos programas de melhoria contínua. XXVI ENEGEP - Fortaleza, CE, Brasil, 9.

Horta, R. e Cabral, P. R. (2008). Cultura Organizacional e Gestão da Inovação Tecnológica. Radar Inovação, dez.

Johann, S. L. (2001). Aspectos Gerenciais da Gestão de pessoas. Rio de Janeiro: FGV Management Cursos de Educação Continuada. 104 p. versão 3, setembro.

Laranja, M.D.; Simões, V.C. \& Fontes, M. (1997). Inovação tecnológica - experiência das empresas portuguesas. Lisboa: Texto.

Luz, R. (2009). Gestão de clima organizacional. 1. ed. Rio de Janeiro : Qualitymark.

Mattos, J. F. C. et. al. (org.s). Manual da Inovação 2008. Brasília: Movimento Brasil Competitivo MBC.

Moreira, C. A. A. (2005, Setembro). Análise da presença do paternalismo na cultura de uma pequena empresa têxtil bem sucedida. In: EGEPE - Encontro de Estudos sobre Empreendedorismo e Gestão de Pequenas Empresas. 4. Curitiba, Anais... Curitiba, 906-917.

Nível de escolaridade na indústria aumenta; $45 \%$ já têm $2^{\circ}$ grau. Economia/Empresas. (2010). Disponível em: <http://economia.ig.com.br/empresas/nivel+de+escolaridade + na + industria+ aumenta+45+ja+tem+2+grau/n1237561542895.html〉. Acesso em: 〈10 abr. 2011〉.

OCDE-Manual de Oslo. (2004). Proposta de diretrizes para coleta e interpretação de dados sobre inovação tecnológica. Finep- tradução português;.

Pelegrino, Fernanda. Reduza a resistência à inovação organizacional e de gestão. (2009). Disponível em: <http://www.facadiferente.sebrae.com.br/2009/07/15/reduza-a-resistencia-a-inovacao-organizacio nal-e-de-gestao/>. Acesso em: <10 abr. 2011〉.

Reis, D. R. (2004). Gestão da Inovação Tecnológica. São Paulo: Manole.

Santos, B de S. (2003). Reconhecer para libertar - os caminhos do cosmopolitismo multicultural. Rio de Janeiro: Ed. Civilização Brasileira.

Santos, N. M. B. F. (2000). Cultura organizacional e desempenho: pesquisa, teoria e aplicação. Lorena: Stiliano.

Vieira, M. M. F.\& Zouain, D. M. (orgs). (2004) Pesquisa Qualitativa em Administração. Rio de Janeiro: Editora FGV. 


\title{
THE INFLUENCE OFORGANIZATIONAL CULTURE IN THE PROCESS OF INNOVATION: THE CASE OF THE AGUIA STORAGE SYSTEMS IN PONTA GROSSA, PARANA
}

\begin{abstract}
This article aims to verify that the processes of innovation developed in Eagle Storage Systems Company S.A, located in Ponta Grossa -Paraná are influenced by organizational culture. To this end, we constructed a literature review on organizational culture and innovation. It is a descriptive research with a qualitative methodological approach, with quantitative data that complement the content analysis from the application of three survey instruments, based on studies of Godoy(2009), directed: Characterization Questionnaire Company Processes and Technology Based Innovation; Scale Culture of Innovation -ECI, and Road map Manager Interview with $\mathrm{R} \& \mathrm{D}$. The results showed that organizational culture profoundly influences the processes of industry innovation, verifying the existence of a culture of innovation in the company solidified.
\end{abstract}

Keywords: Organizational Culture; Innovation; Innovation Culture.

Data do recebimento do artigo: 08/12/2012

Data do aceite de publicação: 20/04/2013

Revista de Administração e Inovação, São Paulo, v. 10, n.2, p. 219-237, abr./jun. 2013. 